\title{
Cinza de bagaço de cana-de-açúcar (CBC) como adição mineral em concretos para verificação de sua durabilidade
}

\author{
Sugarcane bagasse ash (GCB) as \\ mineral admixture in concrete to \\ check its durability
}

\author{
Sérgio Eduardo Fernandes ${ }^{1}$, Mauro Mitsuuchi Tashima ${ }^{2}$, \\ João Cláudio Bassan de Moraes ${ }^{3}$, DaniloBordan Istuque ${ }^{4}$, \\ Cesar Fabiano Fioriti ${ }^{5}$, José Luiz Pinheiro Melges ${ }^{6}$, \\ Jorge Luis Akasaki ${ }^{7}$
}

\author{
${ }^{1}$ Universidade Estadual Paulista - FEIS/UNESP, Departamento de Engenharia Civil, Ilha Solteira, SP \\ e-mail: eng.sergiofernandes@yahoo.com.br \\ ${ }^{2}$ Universidade Estadual Paulista - FEIS/UNESP, Departamento de Engenharia Civil, Ilha Solteira, SP \\ e-mail: mmtashima@dec.feis.unesp.br \\ ${ }^{3}$ Universidade Estadual Paulista - FEIS/UNESP, Departamento de Engenharia Civil, Ilha Solteira, SP \\ e-mail: jotabassan@gmail.com \\ ${ }^{4}$ Universidade Estadual Paulista - FEIS/UNESP, Departamento de Engenharia Civil, Ilha Solteira, SP \\ e-mail: daniloistuque@gmail.com \\ ${ }^{5}$ Universidade Estadual Paulista - FCT/UNESP, Departamento de Planejamento Urbanismo e Ambiente, Presidente \\ Prudente, SP \\ e-mail: fioriti@fct.unesp.br \\ ${ }^{6}$ Universidade Estadual Paulista - FEIS/UNESP, Departamento de Engenharia Civil, Ilha Solteira, SP \\ e-mail: jmelges@dec.feis.unesp.br \\ ${ }^{7}$ Universidade Estadual Paulista - FEIS/UNESP, Departamento de Engenharia Civil, Ilha Solteira, SP \\ e-mail: akasaki@dec.feis.unesp.br
}

\section{RESUMO}

O setor sucroalcooleiro vem se expandindo nos últimos anos, alavancado principalmente pelo advento da bionergia. No Brasil, a produção de cana-de-açúcar vem avançando em áreas destinadas à pecuária extensiva e a outras culturas importantes como a soja, o milho e a laranja, e concerne à geração de energia elétrica pela queima do bagaço (cogeração) e ao uso de etanol como combustível de veículos automotores. Contudo, a produção de açúcar, álcool e energia a partir de cana-de-açúcar pode causar problemas ambientais em decorrência da geração de resíduos como a cinza do bagaço de cana-de-açúcar (CBC). Deste modo, este trabalho apresenta a viabilidade técnica da utilização de cinza resultante do processo de queima do bagaço de cana para a geração de energia como adição mineral, em concretos. Para isso foram realizados ensaios de caracterização química e difração de raios-X na CBC. Produziram-se concretos contendo a CBC nos teores de 5\%, 10\%, 15\% e 20\%, em massa, como substituição parcial ao agregado miúdo. Realizaram-se ensaios mecânicos e, a partir dos resultados obtidos, o traço de concreto que apresentou os melhores resultados foi submetido aos seguintes ensaios de durabilidade: resistência ao ataque químico, absorção por capilaridade, penetração de cloretos e abrasão. O trabalho foi realizado com CBC de baixa atividade pozolânica, entretanto, os resultados indicaram ser possível utilizar a CBC como substituição parcial do agregado miúdo na produção de concretos, pois seus resultados são similares ao concreto sem adição da cinza.

Palavras-chave: concreto, cinza do bagaço da cana-de-açúcar, durabilidade.

\section{ABSTRACT}

The sugar-alcohol sector has been expanding in recent years, mainly by the advent of bioenergy. In Brazil, the production of sugarcane is increasing in areas before used for extensive cattle and other important crops, such as soybeans, corn and orange. In addition concerns about the generation of electricity by burning the bagasse (co-generation) and the use of ethanol as a fuel for motor vehicles. However, production of sugar, 
alcohol and energy from sugarcane can cause environmental problems due to the generation of waste, as the sugarcane bagasse ash (SCBA). In this way, this paper presents a viability study of using this ash from sugarcane bagasse obtained inthepower generation as mineral admixture in concrete. In this study, chemical characterization tests and x-ray diffraction of SCBA were carried out. Concrete were molded with SCBA replacing partially the fine aggregate, in mass, in the following percentages: $5 \%, 10 \%, 15 \%$ and $20 \%$. Mechanical tests were carried out, and from the best results, were assessed indurability tests: resistance to chemical attack, wicking, chloride penetration and abrasion. The study was conductedthat SCBA presents low pozzolanic activity, however, the results indicated that the SCBAcould use as partial replacement of fine aggregate in the production of concrete, because its results are similar to reference concrete without the ash.

Keywords: concrete, sugarcane bagasse ash, durability.

\section{INTRODUÇÃO}

O Brasil é considerado o maior produtor mundial de cana-de-açúcar e seus derivados (açúcar e etanol). Para a safra de cana-de-açúcar (2014/2015), segundo os especialistas, se o clima continuar estável - com chuvas e incidência de sol - a próxima temporada pode bater na casa das 640 milhões de toneladas de cana-de-açúcar. A safra passada (2012/2013) foi responsável pelo processamento de aproximadamente 580 milhões de toneladas de cana de açúcar (CONAB [1]).

Durante a extração do caldo da cana-de-açúcar é gerada grande quantidade de bagaço (aproximadamente 30\% da cana moída), biomassa de suma importância como fonte energética. Cerca de 95\% de todo o bagaço produzido no Brasil são queimados em caldeiras para geração de vapor gerando, como resíduo, a cinza de bagaço, cuja disposição não obedece, na maior parte dos casos, a práticas propícias, podendo-se configurar em sério problema ambiental. Constituída, basicamente, de sílica, $\mathrm{SiO}_{2}$, a cinza do bagaço de cana-de-açúcar (CBC) tem potencial para ser utilizada como adição mineral em argamassas e concretos (CORDEIRO et al. [2]). Estimativas mostram que, para cada tonelada de cana-de-açúcar processada, são produzidos aproximadamente seis quilos de CBC (SALES e LIMA [3]).

Atualmente, um dos problemas enfrentados pelos administradores das usinas é quanto à disposição dessas cinzas residuais. Dessa forma, a indústria da construção civil apresenta um elevado potencial para incorporação de resíduos desta natureza como matéria prima, colaborando para o desenvolvimento tecnológico, ambiental e econômico regional (ROCHA e CHERIAF [4]).

Pesquisas nessa área apontam a necessidade de otimização do processo para a transformação desse resíduo em um material reativo ou pozolânico (GANESAN et al. [5], FRÍAS et al. [6]). Essa mudança no processo das indústrias sucroalcooleiras pode significar um incremento de custos que dificulte a agregação de valor à CBC. A homogeneidade na produção das cinzas não pode ser exigida do processo industrial, que raramente possui controle operacional da temperatura de combustão e do resfriamento das cinzas (SALES e LIMA [3]). Realizados assim, sem controle, esses procedimentos tendem a produzir cinzas sem reatividade pozolânica.

As cinzas que não possuem reatividade podem ser usadas como material de carga inerte, em substituição aos agregados finos em matrizes cimentícias. A crescente elevação do custo da areia natural abre espaço para a entrada de outros materiais, como os resíduos, sendo esses de custo bem inferior aos correlatos naturais (SALES e LIMA [3]).

A CBC tem se mostrado um subproduto viável para aplicação em materiais de construção, desde que sejam observadas suas características intrínsecas, como o alto teor de sílica em forma de quartzo, um dos principais elementos presentes na areia natural (CORDEIRO et al. [2]).

Os critérios utilizados para avaliar a durabilidade do material podem levar em consideração os processos de deterioração. Esses processos estão associados a fenômenos físico-químicos que ocorrem entre os constituintes do concreto e os agentes agressivos, em geral presentes na água, tendo-se como exemplos o ingresso de cloretos e sulfatos, ciclos de molhagem-secagem, carbonatação, reação álcali-agregado, entre outros (MACEDO et al. [7]).

A carbonatação é um fenômeno que ocorre entre a portlandita (hidróxido de cálcio - $\mathrm{CH}$ ) e o $\mathrm{CO}_{2}$ presente no ar. Tal reação depende diretamente da umidade relativa do ar, da concentração de $\mathrm{CO}_{2}$, da pressão de penetração e da temperatura do meio ambiente (ATIS [8]). O CH, no entanto, sofre carbonatação ao mesmo tempo em que o C-S-H (SILVA [9]).

Do ponto de vista físico, ocorre a deposição do carbonato nos poros, obturando-os e tamponando-os, o que diminui a continuidade dos poros ao longo do tempo. Assim, a própria carbonatação consiste em barreira 
eficaz contra si mesma, e a colmatação dos poros colabora com o aumento da dureza superficial do concreto, fato benéfico a concretos sujeitos a abrasão, além de, também, aumentar a proteção contra a ação de sulfatos (HELENE [10]).

Por outro lado, a profundidade de carbonatação de concretos com adição de escória de alto forno e cinza volante pode ser até duas vezes maior do que a profundidade de carbonatação obtida em concretos sem adições. Esse fato pode estar relacionado à redução da alcalinidade advinda da redução da quantidade de cimento na mistura (XUEQUAN et al. [11]).

Outro trabalho, no entanto, concluiu que, quanto maior a resistência à compressão, menor a porosidade e a profundidade de carbonatação de concretos com cinza volante, e que o aumento da porosidade resulta em aumento da profundidade de carbonatação para uma resistência à compressão constante, ou seja, a resistência mecânica não é o parâmetro único para o controle da carbonatação (ATIS [12]).

A incorporação de adições minerais em concretos pode ter um efeito benéfico sobre algumas de suas propriedades, fato que pode ser explicado devido ao refinamento dos poros e dos grãos, aumento da tortuosidade dos canais e redução da interconectividade dos poros. A substituição parcial de areia por CBC aumentou a resistência à compressão de argamassas, aos 28 dias, para teores entre 20\% e 30\% (LIMA et al. [13]).

Nesse contexto, este trabalho teve como objetivo avaliar a resistência mecânica e também a durabilidade de concreto com adição mineral de CBC em substituição parcial ao agregado miúdo por meio dos ensaios de resistência ao ataque químico, absorção por capilaridade, penetração de cloretos e abrasão. Os valores obtidos nesses ensaios foram comparados aos obtidos para um concreto sem CBC (referência).

\section{MATERIAIS E MÉTODOS}

Todo o programa experimental foi realizado no Laboratório de Engenharia Civil da Companhia Energética de São Paulo (CESP) e no Laboratório de Engenharia Civil da Universidade Estadual Paulista (UNESP), ambos situados no município de Ilha Solteira, Brasil.

\subsection{Cimento}

Como este trabalho investigou o uso de uma adição mineral, através da substituição parcial de areia por CBC, escolheu-se um cimento sem adições para qualificar melhor a reatividade do material. Deste modo, o cimento utilizado foi o CPV-ARI (cimento Portland de alta resistência inicial) que embora possua baixo teor de adição em sua composição, pode ser encontrado mais facilmente no mercado do que o CPI (cimento Portland sem adições). As propriedades físicas e químicas do cimento utilizado estão apresentadas na Tabela 1.

Tabela 1:Propriedades químicas e físicas do cimento utilizado nos concretos (ABNT NBR 11578 [14]).

\begin{tabular}{|c|c|c|}
\hline \multicolumn{2}{|c|}{ Material retido na \# 200 (\%) } & 0,05 \\
\hline \multicolumn{2}{|c|}{ Blaine $\left(\mathrm{cm}^{2} / \mathrm{g}\right)$} & 4.490 \\
\hline \multicolumn{2}{|c|}{ Massa específica aparente $\left(\mathrm{g} / \mathrm{cm}^{3}\right)$} & 0,99 \\
\hline \multicolumn{2}{|c|}{ Massa específica absoluta (g/cm³) } & 3,14 \\
\hline \multicolumn{2}{|c|}{ Início de pega (h:min) } & 01:58 \\
\hline \multirow{2}{*}{$\begin{array}{c}\text { Resistência à } \\
\text { compressão(MPa) }\end{array}$} & 7 dias & 39,60 \\
\hline & 28 dias & 51,50 \\
\hline \multirow{10}{*}{ Análise química (\%) } & Perda ao fogo $-1.000^{\circ} \mathrm{C}$ & 4,50 \\
\hline & Resíduo insolúvel & 0,85 \\
\hline & $\mathrm{SiO}_{2}$ & 18,21 \\
\hline & $\mathrm{Fe}_{2} \mathrm{O}_{3}$ & 3,16 \\
\hline & $\mathrm{Al}_{2} \mathrm{O}_{3}$ & 6,18 \\
\hline & $\mathrm{CaO}$ & 62,31 \\
\hline & $\mathrm{MgO}$ & 0,65 \\
\hline & $\mathrm{SO}_{3}$ & 2,81 \\
\hline & $\mathrm{Na}_{2} \mathrm{O}$ & 0,19 \\
\hline & $\mathrm{K}_{2} \mathrm{O}$ & 0,72 \\
\hline
\end{tabular}




\subsection{Agregados}

Foi utilizada areia natural como agregado miúdo e brita basáltica como agregado graúdo, em que suas respectivas caracterizações basearam-se na ABNT NBRNM 248 [15]. Os resultados são apresentados nas Tabelas 2 e 3.

Tabela 2: Composição granulométrica do agregado miúdo.

\begin{tabular}{c|c|c|c|c|c|c|c|c|c}
\hline \multirow{2}{*}{$\begin{array}{c}\text { Peneiras } \\
(\mathbf{m m})\end{array}$} & \multicolumn{10}{c}{ \% Retida acumulada } \\
\cline { 2 - 10 } & $\mathbf{0 , 0 7 5}$ & $\mathbf{0 , 1 4 9}$ & $\mathbf{0 , 2 9 7}$ & $\mathbf{0 , 5 9 5}$ & $\mathbf{1 , 1 9}$ & $\mathbf{2 , 3 8}$ & $\mathbf{4 , 7 6}$ & $\mathbf{6 , 3 0}$ & $\mathbf{9 , 5 1}$ \\
\hline & 100 & 92 & 62 & 32 & 18 & 4 & 0 & 0,0 & 0,0 \\
\hline
\end{tabular}

\begin{tabular}{|c|c|c|c|c|c|c|}
\hline \multirow{2}{*}{$\begin{array}{c}\text { Diâmetro } \\
\text { máximo } \\
(\mathrm{mm})\end{array}$} & \multirow{2}{*}{$\begin{array}{c}\text { Módulo de } \\
\text { finura }\end{array}$} & \multirow{2}{*}{$\begin{array}{c}\text { Absorção } \\
\text { (\%) }\end{array}$} & \multirow{2}{*}{$\begin{array}{c}\text { Material } \\
\text { pulverulento }\end{array}$} & \multirow{2}{*}{$\begin{array}{l}\text { Matéria } \\
\text { orgânica }\end{array}$} & \multicolumn{2}{|c|}{ Massa específica } \\
\hline & & & & & $\begin{array}{c}\text { Aparente } \\
\left(\mathrm{g} / \mathrm{cm}^{3}\right)\end{array}$ & $\begin{array}{c}\text { Absoluta } \\
\left(\mathrm{g} / \mathrm{cm}^{3}\right)\end{array}$ \\
\hline 8 & 2,07 & 0,28 & 0,86 & + clara & 1,543 & 2,631 \\
\hline
\end{tabular}

Tabela 3: Composição granulométrica do agregado graúdo.

\begin{tabular}{|c|c|c|c|c|c|c|c|c|c|c|c|c|}
\hline \multirow{2}{*}{$\begin{array}{c}\text { Peneiras } \\
(\mathrm{mm})\end{array}$} & \multicolumn{12}{|c|}{ \% Retida acumulada } \\
\hline & 0,149 & 0,297 & \multicolumn{2}{|c|}{0,595} & 1,19 & 2,38 & 4,76 & 6,30 & 9.51 & 12,70 & 19,00 & 25,4 \\
\hline & 100,0 & 100,0 & \multicolumn{2}{|c|}{100,0} & 100,0 & 100,0 & 99 & 99 & 85 & 62 & 3 & 0,0 \\
\hline \multirow{2}{*}{\multicolumn{2}{|c|}{$\begin{array}{c}\text { Dimensão } \\
\text { máxima } \\
\text { característica } \\
\text { (mm) }\end{array}$}} & \multirow{2}{*}{\multicolumn{2}{|c|}{$\begin{array}{l}\text { Módulo } \\
\text { de finura }\end{array}$}} & \multirow{2}{*}{\multicolumn{2}{|c|}{$\begin{array}{c}\text { Absorção } \\
(\%)\end{array}$}} & \multirow{2}{*}{\multicolumn{2}{|c|}{$\begin{array}{c}\text { Material } \\
\text { pulverulento }\end{array}$}} & \multicolumn{5}{|c|}{ Massa específica } \\
\hline & & & & & & & & $\begin{array}{c}\text { s.s.s. } \\
\left(\mathrm{g} / \mathbf{c m}^{3}\right)\end{array}$ & $\begin{array}{r}\text { Apa } \\
\text { (g/ }\end{array}$ & nte & $\begin{array}{r}\text { Absolu } \\
\left(\mathrm{g} / \mathrm{cm}^{3}\right.\end{array}$ & \\
\hline \multicolumn{2}{|c|}{19,00} & 6,87 & \multicolumn{3}{|c|}{1,16} & \multicolumn{2}{|l|}{1,20} & 2,945 & \multicolumn{2}{|c|}{1,585} & \multicolumn{2}{|l|}{3,014} \\
\hline
\end{tabular}

\subsection{Aditivo}

Fez-se o uso de aditivo superplastificante em todos os traços de concreto sem alterar a relação água/cimento. O aditivo redutor de água escolhido se trata de policarboxilato, onde suas características são apresentadas na Tabela 4.

Tabela 4: Características técnicas do aditivo utilizado.

\begin{tabular}{c|c}
\hline Função principal & Superplastificante \\
\hline Composição básica & Solução de policarboxilato em meio aquoso \\
\hline Dosagem máxima & $1,5 \%$ em relação ao peso do cimento \\
\hline pH & $5,0 \pm 1,0$ \\
\hline Massa específica & $1,07 \mathrm{~kg} \pm 0,02 \mathrm{~kg} / \mathrm{l}$ \\
\hline
\end{tabular}

\subsection{Cinza do bagaço da cana-de-açúcar}

A amostra de CBC foi coletada em uma usina da região noroeste paulista, proveniente de sua lagoa de decantação. O bagaço da cana-de-açúcar é queimado em caldeiras, gerando a CBC (Figura 1), que se mistura com a água no lavador de gases. Esta água, juntamente com a água da lavagem da cana, é levada para a lagoa de decantação, onde o líquido ao ser separado das partes sólidas da cinza é reaproveitado pela usina. 


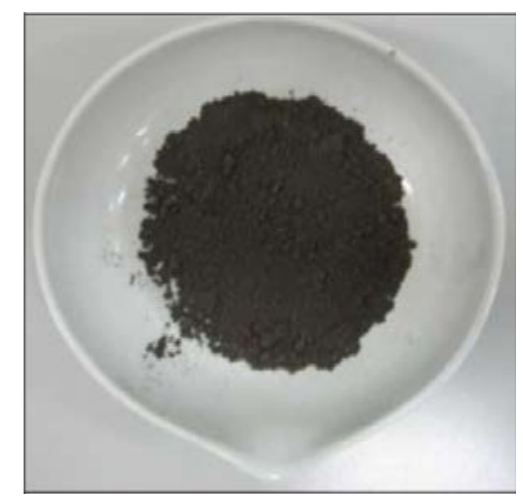

Figura 1: Aspecto da CBC incorporada nos concretos.

Na sequência, a Tabela 5 apresenta a composição química da CBC, segundo a ABNT NBR 12653 [16], onde se percebe que a $\mathrm{CBC}$ utilizada está em conformidade com as exigências químicas para material pozolânico, contendo alto teor de $\mathrm{SiO}_{2}+\mathrm{Al}_{2} \mathrm{O}_{3}+\mathrm{Fe}_{2} \mathrm{O}_{3}$, reduzida perda ao fogo e baixo teor de álcalis disponíveis.

Tabela 5: Análise química da amostra de CBC.

\begin{tabular}{c|c|c|c|c|c|c|c|c}
\hline $\mathrm{SiO}_{2}$ & $\mathrm{Al}_{2} \mathbf{O}_{3}$ & $\mathbf{F e}_{2} \mathbf{O}_{3}$ & $\mathbf{C a O}$ & $\mathbf{M g O}$ & $\mathbf{S O}_{3}$ & $\mathbf{S i O}_{2}+\mathbf{A l}_{2} \mathbf{O}_{3}+\mathbf{F e}_{2} \mathbf{O}_{3}$ & $\begin{array}{c}\text { Perda } \\
\text { fogo }\end{array}$ & Umidade \\
\hline 44,30 & 8,74 & 3,43 & 9,60 & 0,76 & 0,35 & 56,48 & 32,59 & 2,28 \\
\hline
\end{tabular}

As cinzas foram homogeneizadas e, para a sua secagem, permaneceram em estufa por 24 horas à temperatura de $110^{\circ} \mathrm{C}$ e mais 24 horas expostas ao Sol.

Por fim, realizou-se a difração de raios-x na CBC empregada nos concretos (Figura 2), que exibe picos intensos de alfa óxido de silício e quartzo alfa, o que evidencia a existência de suas fases cristalinas. No entanto, é possível notar um pequeno desvio na linha de base no ângulo (20) $20^{\circ}$, que sugere indícios de fase amorfa.

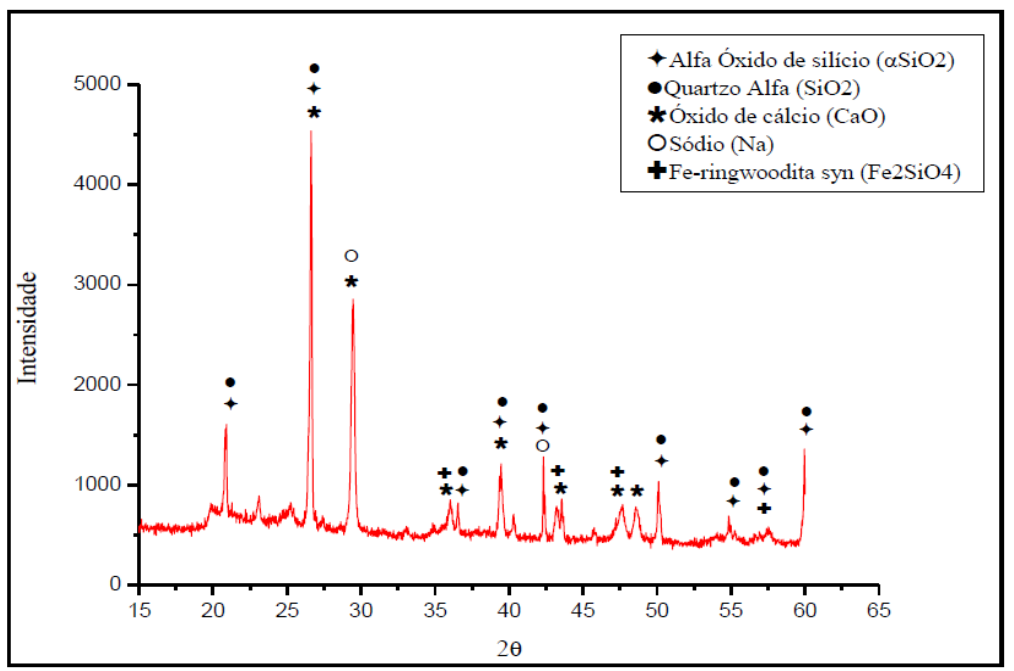

Figura 2: Difratrograma da CBC usada nos concretos.

\subsection{Composições dos concretos}

Os resultados da análise química e da difração de raios-x indicaram um material pouco eficaz como pozolana, na substituição do cimento. Deste modo, optou-se pela adição da CBC substituindo-se parte da massa do agregado miúdo. 
Foi realizada uma investigação para definir a relação a/c e a consistência que seriam adequadas a todos os traços com substituição parcial de agregado miúdo por CBC, sendo necessário o uso de aditivo superplastificante. Adotou-se a relação a/c 0,50 e partindo da relação 1:m de 1:5, fez-se a substituição do agregado miúdo por CBC nas porcentagens 5\%, 10\%, 15\% e 20\%. Utilizou-se 1,5\% de aditivo superplastificante, em relação ao peso do cimento, em cada traço produzido.

O ensaio de abatimento pelo tronco de cone (slumptest), conforme a ABNT NBRNM 67 [17], foi realizado a fim de se verificar as condições de trabalhabilidade dos concretos produzidos. Na Tabela 6 é apresentada a composição dos traços utilizados, juntamente com seus respectivos valores teste de abatimento pelo tronco de cone e teor de ar incorporado.

Tabela 6: Composição final dos traços dos concretos.

\begin{tabular}{|c|c|c|c|c|c|c|c|}
\hline Traço & $\begin{array}{c}\text { Cimento } \\
\left(\mathrm{kg} / \mathrm{m}^{3}\right)\end{array}$ & $\begin{array}{c}\text { Areia } \\
\left(\mathrm{kg} / \mathrm{m}^{3}\right)\end{array}$ & $\begin{array}{c}\text { Brita } \\
\left(\mathrm{kg} / \mathrm{m}^{3}\right)\end{array}$ & $\begin{array}{c}\text { CBC } \\
\left(\mathrm{kg} / \mathrm{m}^{3}\right)\end{array}$ & $\begin{array}{c}\text { Água } \\
\left(\mathbf{k g} / \mathbf{m}^{3}\right)\end{array}$ & $\begin{array}{l}\text { Aditivo } \\
\left(\mathrm{kg} / \mathrm{m}^{3}\right)\end{array}$ & $\begin{array}{c}\text { Ensaio de } \\
\text { abatimen } \\
\text { to pelo } \\
\text { tronco de } \\
\text { cone }(\mathrm{mm})\end{array}$ \\
\hline Referência & 376,40 & 730,10 & 1151,70 & - & 188,15 & 5,65 & 130,00 \\
\hline $5 \%$ & 377,40 & 695,60 & 1154,90 & 36,60 & 183,04 & 5,66 & 70,00 \\
\hline $10 \%$ & 376,30 & 657,00 & 1151,40 & 73,00 & 182,46 & 5,64 & 80,00 \\
\hline $15 \%$ & 375,20 & 618,70 & 1148,00 & 109,20 & 181,97 & 5,63 & 90,00 \\
\hline $20 \%$ & 374,10 & 580,60 & 1144,70 & 145,10 & 181,39 & 5,61 & 110,00 \\
\hline
\end{tabular}

Cabe mencionar que ocorreu um gradativo escurecimento na coloração dos concretos produzidos em virtude de acréscimo do teor de CBC.

\subsection{Programa experimental de ensaios}

\subsubsection{Resistência à compressão}

Foram moldados quatro corpos de prova cilíndricos (20 cm de altura x $10 \mathrm{~cm}$ de diâmetro), por traço, para cada idade, com ruptura aos 7 e 28 dias, tomando-se como resistência final a média aritmética entre eles. Os corpos de prova foram moldados e curados seguindo as prescrições da ABNT NBR 5738 [18] e ABNT NBR 5739 [19]. A melhor porcentagem de CBC no ensaio de resistência à compressão foi utilizada nos ensaios de durabilidade, assim como a referência.

\subsubsection{Resistência à tração por compressão diametral}

Este ensaio seguiu as recomendações da ABNT NBR 7222 [20], em que foram moldados quatro corpos de prova cilíndricos (20 cm de altura x $10 \mathrm{~cm}$ de diâmetro), por traço, para cada idade, com ruptura aos 7 e 28 dias, tomando-se como resistência final a média aritmética.

\subsubsection{Resistência ao ataque químico (ácido lático)}

O ensaio de resistência ao ataque químico sob a ação de ácidos foi realizado pelas avaliações dos resultados de perda de massa, aspecto visual e queda de resistência mecânica, quando os corpos de prova foram submetidos a ciclos de imersão e secagem em solução contendo ácido lático.

Foram moldados três corpos de prova cilíndricos $(20 \mathrm{~cm}$ de altura x $10 \mathrm{~cm}$ de diâmetro), por traço, onde os mesmos foram inseridos em soluções contendo ácido lático, em uma concentração igual a 14\%. O ácido lático é encontrado em indústrias de laticínio, a partir da fermentação da lactose ou em indústrias de produtos químicos. A ação deletéria deste agente agressivo sobre o concreto consiste na dissolução do $\mathrm{Ca}(\mathrm{OH})_{2}$, a partir da superfície do concreto, levando à lixiviação deste produto de hidratação.

O modelo de ensaio teve como base os trabalhos de ANDRADE et al. [21] e DAL MOLIN et al. [22]. Ao término do período de cura em câmara úmida, 28 dias, os corpos de prova foram retirados e secos ao ar por 24 horas e, logo após, pesados. Após a pesagem, foram imersos em ácido lático por 5 dias. Posteriormente foram retirados do recipiente contendo ácido, e lavados para retirar os resíduos de concreto e 
dos sais solúveis resultantes das trocas químicas entre o cimento e a solução ácida depositados na sua superfície, deixando-os secar ao ar livre por 6 dias. Passado este período, concluiu-se um ciclo com 11 dias, iniciando-se outro. Depois, foi realizada uma nova pesagem e a imersão novamente, até que os corpos de prova completassem 2 ciclos de ensaio. As pesagens realizadas indicaram a perda de massa em cada ciclo para um mesmo corpo de prova.

\subsubsection{Absorção por capilaridade}

O ensaio seguiu as prescrições da ABNT NBR 9779 [23], em que foram utilizados três corpos de prova cilíndricos (20 cm de altura x $10 \mathrm{~cm}$ de diâmetro), por traço, para cada idade, com ruptura aos 7 e 28 dias, tomando-se como absorção final sua média aritmética.

\subsubsection{Penetração de cloretos}

O ensaio foi realizado pelo método "Colorimétrico de aspersão de nitrato de prata”, observado após 4 ciclos de molhagem e secagem e iniciado após 28 dias de cura. Foram utilizados três corpos de prova cilíndricos (20 cm de altura x $10 \mathrm{~cm}$ de diâmetro), por traço de concreto. A exposição a esse tipo de ataque em ambiente marinho seria por volta de 3,5\% de $\mathrm{NaCl}$ de concentração, mas segundo SILVA [24], a observação da frente de penetração nesse período de tempo do ensaio seria muito pequena. Por isso, a concentração utilizada foi de $10 \%$ de $\mathrm{NaCl}$. Após o período de cura, os corpos de prova foram deixados em local com umidade ambiente por 4 dias. Na sequência, foram imersos com metade da altura na solução de $\mathrm{NaCl}$ por 3 dias. Após este período, os corpos de prova passaram por secagem de 4 dias, completando um ciclo.

\subsubsection{Abrasão}

Este ensaio é uma referência ao método prescrito na ASTM C 1138 [25], em que foi realizado com a confecção de um corpo de prova cilíndrico (10 cm de altura x $30 \mathrm{~cm}$ de diâmetro), por traço, para 7 e 28 dias. O desgaste do corpo de prova é verificado pelo atrito das esferas de aço na superfície do mesmo, causado pela abrasão na superfície. Esse desgaste é calculado por meio da porcentagem da massa inicial do corpo de prova, no decorrer de 72 horas de ensaio, sendo pesado antes de iniciar o ensaio e após 10, 24, 48 e 72 horas.

\section{RESULTADOS}

\subsection{Resistência à compressão}

Conforme a Figura 3 nota-se que o traço com 20\% de adição de CBC foi o que obteve os melhores resultados de resistência à compressão em comparação com as séries de traços produzidos, enquanto comparado com a referência, apresentou resultado semelhante.

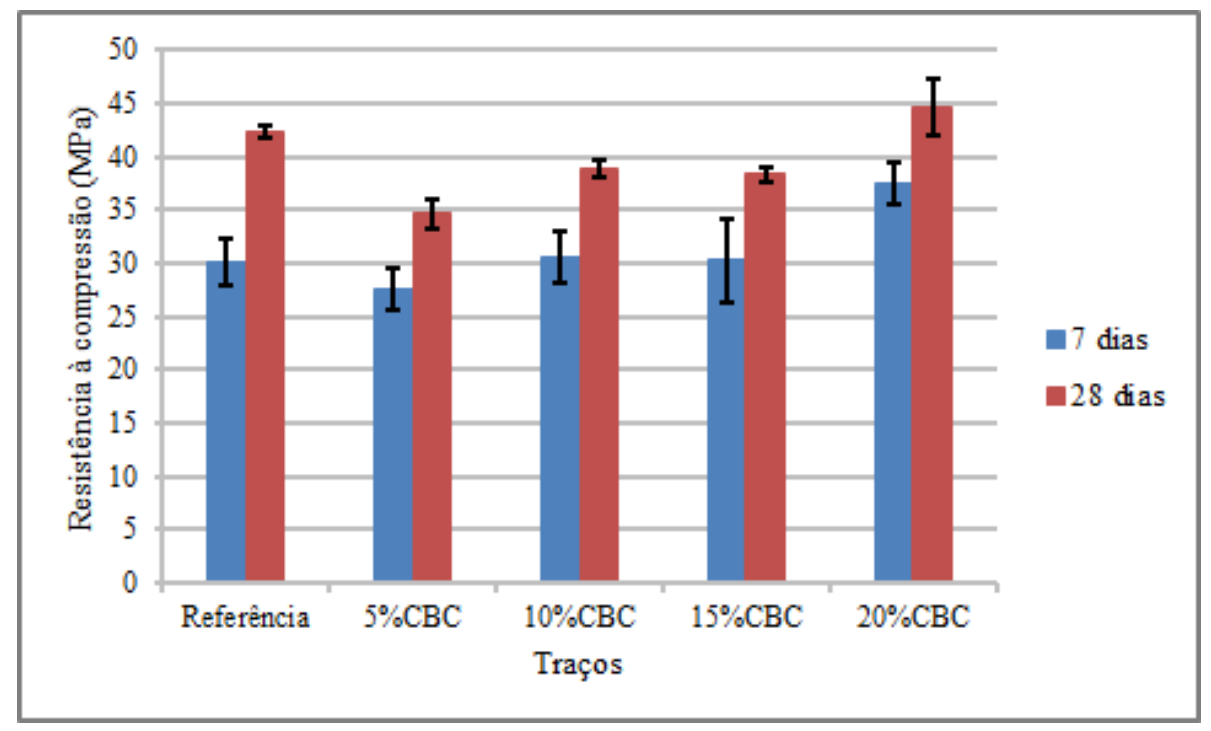

Figura 3: Resistência à compressão dos concretos. 


\subsection{Resistência à tração por compressão diametral}

Pela Figura 4, percebe-se que o comportamento da resistência à tração por compressão diametral seguiu a mesma evolução dos concretos quanto a resistência à compressão, assim, o traço com 20\% de adição de CBC foi o que apresentou resultados um pouco superiores em comparação aos demais traços.

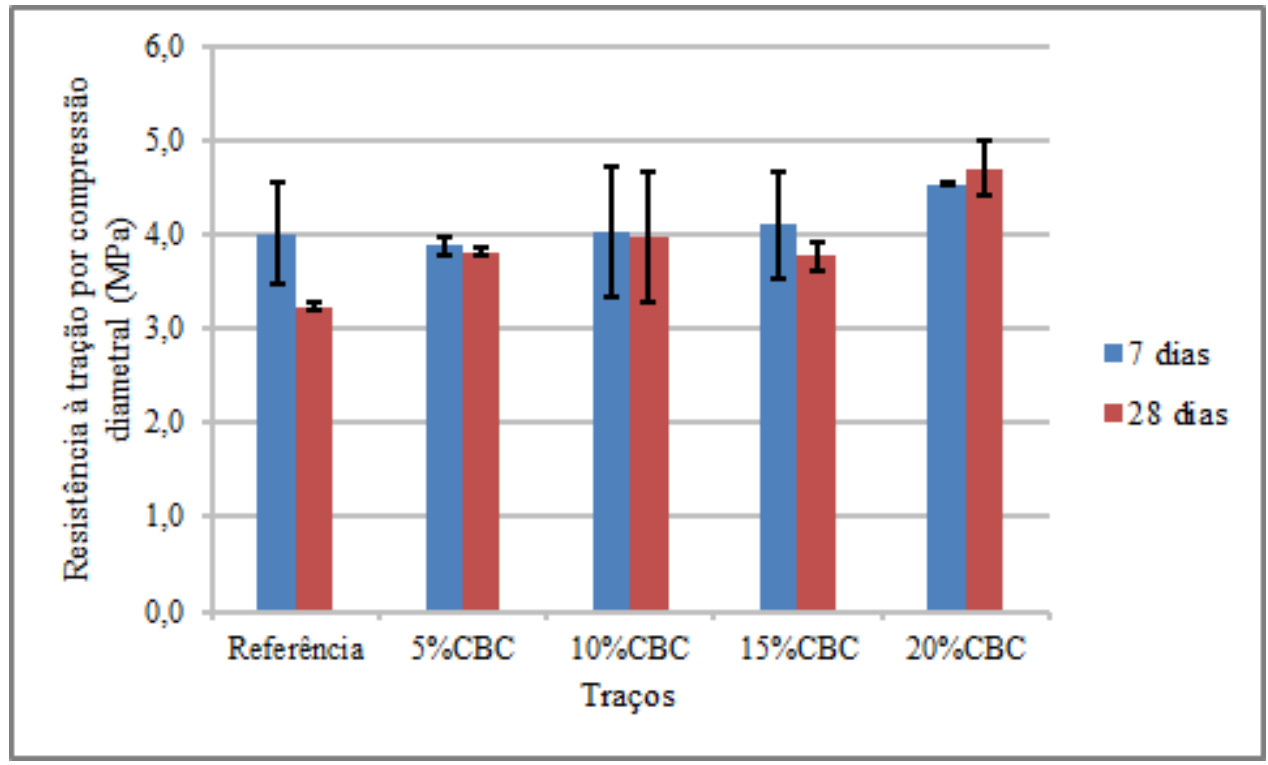

Figura 4: Resistência à tração por compressão diametral dos concretos.

\subsection{Resistência ao ataque químico (ácido lático)}

A Figura 5 apresenta os resultados da perda de massa (\%) por ataque químico em ciclos, nela percebe-se que o percentual de perda de massa do traço referência, mesmo em pouca diferença, foi maior que o do traço com 20\% de CBC, principalmente no ciclo - 02 (final).

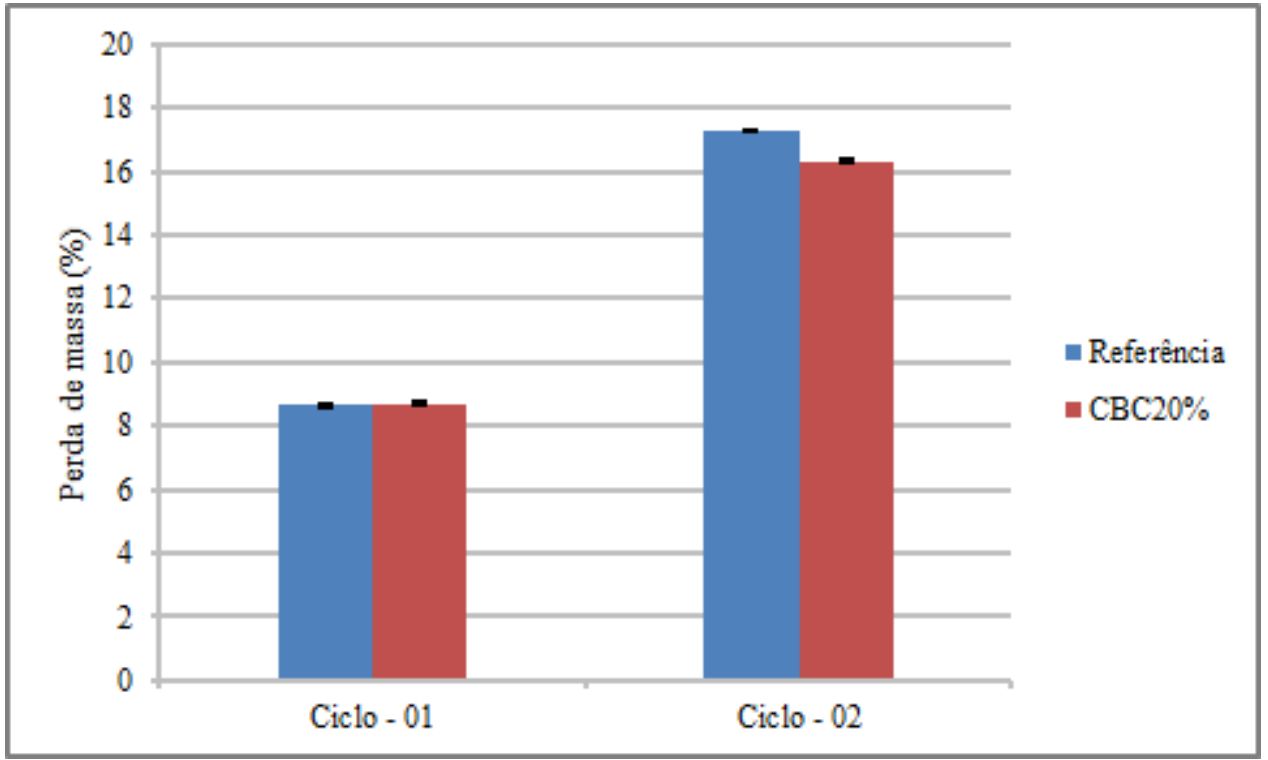

Figura 5: Perda de massa (\%) por ataque químico. 


\subsection{Absorção por capilaridade}

Os resultados deste ensaio estão apresentados na Figura 6, e através da Figura 7 pode-se notar a lâmina de umidade por capilaridade em um corpo de prova de concreto com 20\% de CBC, em que ocorreu um maior refinamento dos poros indicando uma ascensão capilar pouco maior do traço com CBC quando comparado ao traço referência.

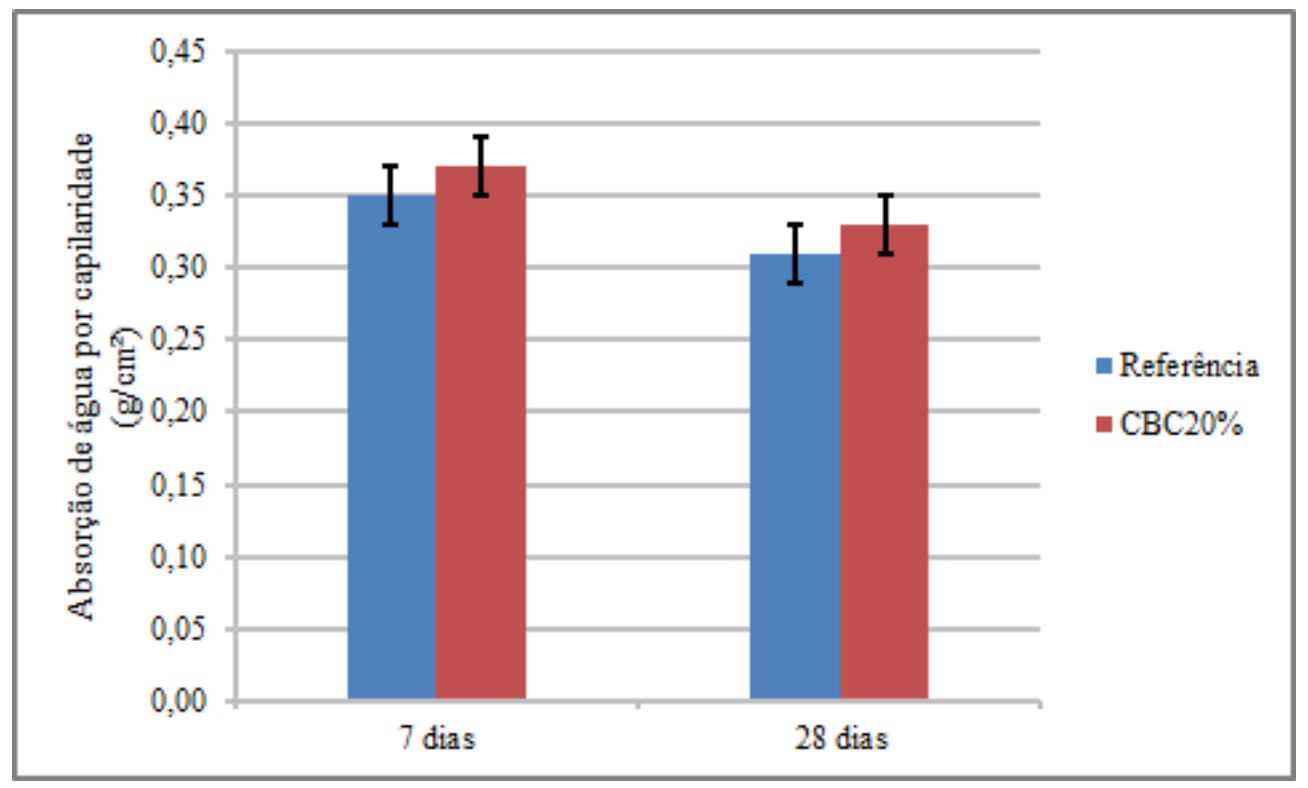

Figura 6: Absorção de água por capilaridade $\left(\mathrm{g} / \mathrm{cm}^{2}\right)$.

\subsection{Penetração de cloretos}

A Tabela 7 apresenta os resultados frente à penetração de cloretos, em que o traço com 20\% de CBC apresentou menor média de profundidade de penetração quando comparado ao traço de referência.

Tabela 7: Média de profundidade de penetração de cloretos (mm).

\begin{tabular}{l|l}
\hline Traços & $\begin{array}{l}\text { Média de penetração dos cloretos } \\
(\mathrm{mm})\end{array}$ \\
\hline Referência & $3,30 \pm 1,50$ \\
\hline $20 \%$ CBC & $2,30 \pm 1,20$ \\
\hline
\end{tabular}

\subsection{Abrasão}

Na Tabela 8 podem ser vistos os resultados de desgaste por abrasão após o período de 72 horas, em que o traço com 20\% de CBC apresentou menor percentual de perda de massa quando comparado com o traço referência.

Tabela 8: Perda de massa (\%) após o período de 72 horas.

\begin{tabular}{l|l}
\hline Traços & Perda de massa (\%) \\
\hline Referência & 10,30 \\
\hline $20 \%$ CBC & 5,00 \\
\hline
\end{tabular}




\section{DISCUSSÃO}

\subsection{Ensaio de abatimento pelo tronco de cone}

Foi observado durante o preparo das amostras de concreto uma acentuada interferência da cinza residual de bagaço de cana no abatimento do concreto, tendo como consequência a redução do abatimento da ordem de $46,15 \%, 38,46 \%, 30,77 \%$ e $15,38 \%$, respectivamente para os traços com $5 \%, 10 \%, 15 \%$ e $20 \%$ de CBC, quando comparados com o traço referência.

Porém isso não foi observado no trabalho de MODANIA e VYAWAHAREB [26], que também trabalharam com substituição da areia por CBC (10\% e 20\%), e constataram que com a fração de substituição proposta não ocorreu perda de trabalhabilidade dos concretos produzidos. Para MOLIN FILHO [27], que utilizou $10 \%$ de CBC como substituto da areia em concretos autoadensáveis, a trabalhabilidade do concreto não foi alterada.

Como não foi observado exsudação no concreto de referência, não se pode analisar, de forma comparativa, o efeito da CBC na retenção da água de amassamento no interior da mistura, sendo constatado o mesmo comportamento para todos os traços produzidos.

Para CORDEIRO [28], a redução ou até a inexistência de exsudação em concretos com adição e cinzas residuais está relacionada diretamente a superfície específica do material empregado. GIAMMUSSO [29] considera que materiais com composições granulométricas reduzidas, maior superfície específica, apresentam tendência para uma maior retenção de água devido à adsorção do líquido na superfície dos grãos, fenômeno este que explica a inexistência de exsudação em concretos com presença de adições minerais.

\subsection{Avaliação de propriedades mecânicas}

Para todas as séries de traços avaliadas foi possível obter valores que permitem indicar uma distribuição do tipo normal para os valores obtidos nos ensaios de resistência à compressão e de resistência à tração por compressão diametral, dos concretos com e sem a adição de CBC. Para o concreto do traço $20 \%$ de CBC foi possível verificar queos valores tanto de resistência à compressão como de resistência à tração por compressão diametral, para as duas idades de realização dos ensaios, foram maiores quando comparados aos demais traços produzidos, enquanto foi muito semelhante quando comparado ao traço de referência.

No traço de referência os valores de resistência à compressão, aos 28 dias, foram maiores que os valores dos traços com $5 \%, 10 \%$ e $15 \%$ de CBC, respectivamente sendo de $18,16 \%, 8,25 \%$ e $0,94 \%$. O traço com 20\% de CBC apresentou resultados de compressão 5,42\% maiores que o traço de referência, ou seja, à medida que se aumentou o percentual de adição de CBC ocorreu uma melhora dos resultados.

Com relação aos ensaios de resistência à tração por compressão diametral, o traço de referência superou em 2,38\% o traço com $5 \%$ de CBC, aos 28 dias. Os traços com $10 \%$, $15 \%$ e $20 \%$ de CBC apresentaram resultados de 2,38\%, 4,76\% e 19,05\%, respectivamente, maiores que o concreto de referência.

SOUTO [30] obteve aumento nos resultados de resistência à compressão axial dos concretos estudados com 15\% de substituição da areia por CBC, chegando a 11,81\% superior em comparação ao concreto sem adição de CBC, efeito esse atribuído ao preenchimento dos poros da matriz cimentícia pelo grão de CBC.

MOLIN FILHO [27] não observou diferenças consideráveis nos valores obtidos nas resistências à compressão axial e à tração, em concretos autoadensáveis com substituição de $10 \%$ da areia por CBC em relação ao concreto autoadensável sem $\mathrm{CBC}$, oportunidade em que não foram realizados ensaios de durabilidade do material.

Sabe-se que, quanto menor a resistência à compressão, maior será o teor de vazios de um concreto e maior será sua frente de carbonatação, pois os poros podem facilitar a entrada de $\mathrm{CO}_{2}$ no material e, por consequência, desencadear a reação com seus componentes (ATIS [12]). Desse modo, o traço de concreto com 20\% de adição de CBC apresentou os melhores resultados, assim, tanto esse compósito como o traço referência foram submetidos aos ensaios de durabilidade que compõem o programa experimental e que são apresentados na sequência.

\subsection{Avaliação de propriedades relacionadas à durabilidade}

Nos ensaios de resistência frente ao ataque químico (ácido lático), os resultados da medição da perda de massa (\%) ao final do ciclo - 01 (inicial) foram praticamente idênticos, enquanto que ao final do ciclo - 02 (final) o traço com $20 \%$ de CBC apresentou uma perda de massa 1,0\% menor que o traço referência. Diante 
do exposto, os valores de resistência ao ataque químico podem ser considerados equivalentes entre si, além disso, percebeu-se durante a realização dos ensaios que o desgaste dos corpos de prova foi semelhante em ambos os traços analisados. Isso também indica que o concreto com teores de CBC maiores que o utilizado no trabalho tem a capacidade de impedir com maior sucesso a entrada de agentes agressores, revelando sua maior capacidade de impermeabilização. A Figura 6 apresenta algumas imagens dos corpos de prova após a realização das séries de ensaios de resistência ao ataque químico.
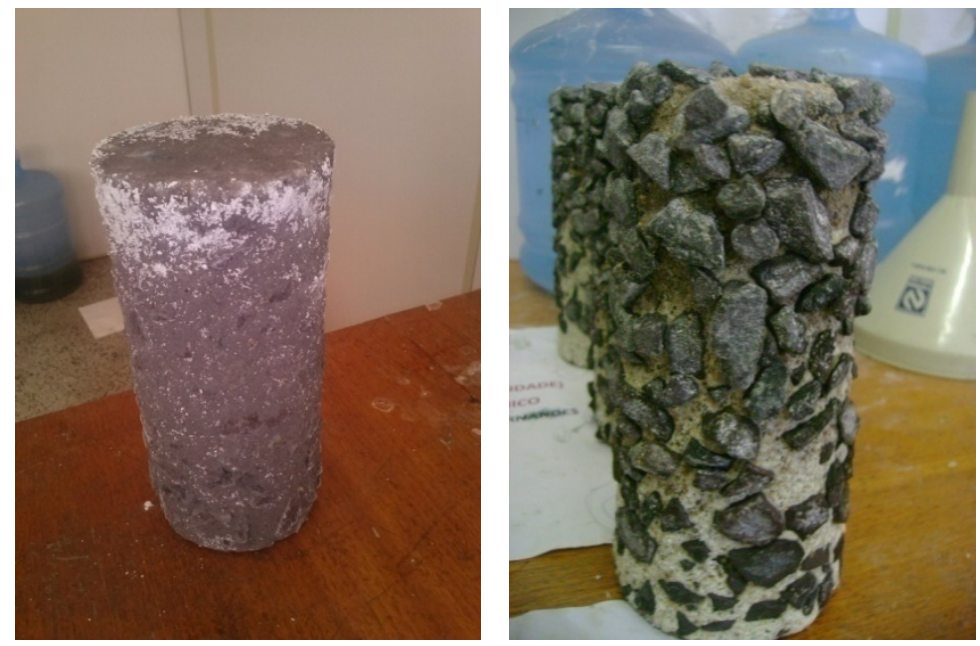

Figura 6: Corpos de prova de concreto com $20 \%$ de CBC ao final do ensaio de ataque químico: a) Ciclo - 01 ; b) Ciclo 02 .

SINGH et al. [31] também verificaram que a deterioração química causada por ácido sulfúrico $\left(\mathrm{H}_{2} \mathrm{SO}_{4}, \mathrm{~N} / 60\right)$, medida por meio de expansões de prismas, foi significativamente menor nas pastas de cimento com CBC.

Quanto aos ensaios de absorção por capilaridade, o traço de referência apresentou resultado ligeiramente inferior ao do traço com $20 \%$ de CBC, ou seja, com valores de $2,0 \mathrm{~g} / \mathrm{cm}^{2}$ menores que o traço com CBC, tanto aos 7 como aos 28 dias. Cabe mencionar que no decorrer da idade de 7 para 28 dias, os dois traços estudados sofreram razoável redução de absorção por capilaridade, sendo de 11,43\% para o traço de referência e de 10,81\% para o traço com $20 \%$ de CBC. Assim, também se podem considerar os valores obtidos nos dois traços de concreto equivalentes entre si. Na Figura 7 pode-senotar a lâmina de umidade por capilaridade em um corpo de prova de concreto com 20\% de CBC.

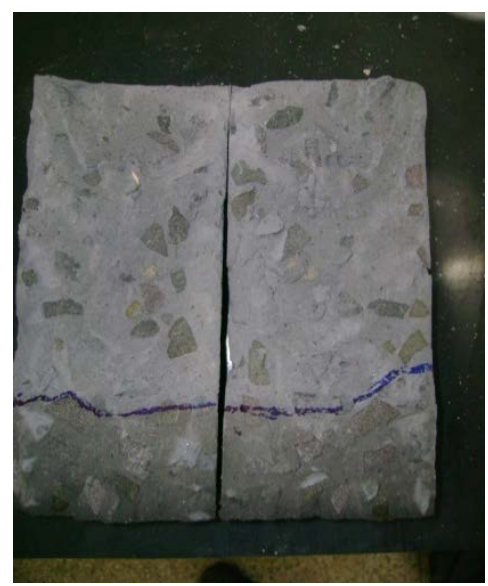

Figura 7: Detalhe do nível (em azul) da lâmina de umidade por capilaridade de um corpo de prova com 20\% de CBC.

BAGUANT [32] substituiu 75\% de areia por CBC em concretos e concluiu que para esse teor de substituição 
ocorre similaridade nos dados referentes aos ensaios de absorção por capilaridade, além disso, apresenta maior resistência ao congelamento-descongelamento.

Para MACEDO [33] que utilizou 10\% de CBC em substituição da areia de argamassas, em todos os casos, ocorreu a redução da absorção por capilaridade, atribuída ao preenchimento dos vazios, dificultando o ingresso de agentes agressivos à argamassa.

Com relação aos ensaios frente à penetração de cloretos, os resultados mostraram que ao final do processo o traço com $20 \%$ de CBC apresentou uma média de penetração de cloretos 30,30\% menor que o traço de referência. Isso indica que as amostras de CBC possuem baixa acidez influenciando o aumento da alcalinidade do concreto, o que dificultou o avanço da frente de carbonatação. A Figura 8 mostra o detalhe (faixa esbranquiçada) das bordas dos corpos de prova identificando o local de reação entre nitrato de prata $\left(\mathrm{AgNO}_{3}\right)$ e o cloreto de sódio $(\mathrm{NaCl})$, despontando a região onde há a penetração dos íons de cloreto nos concretos.

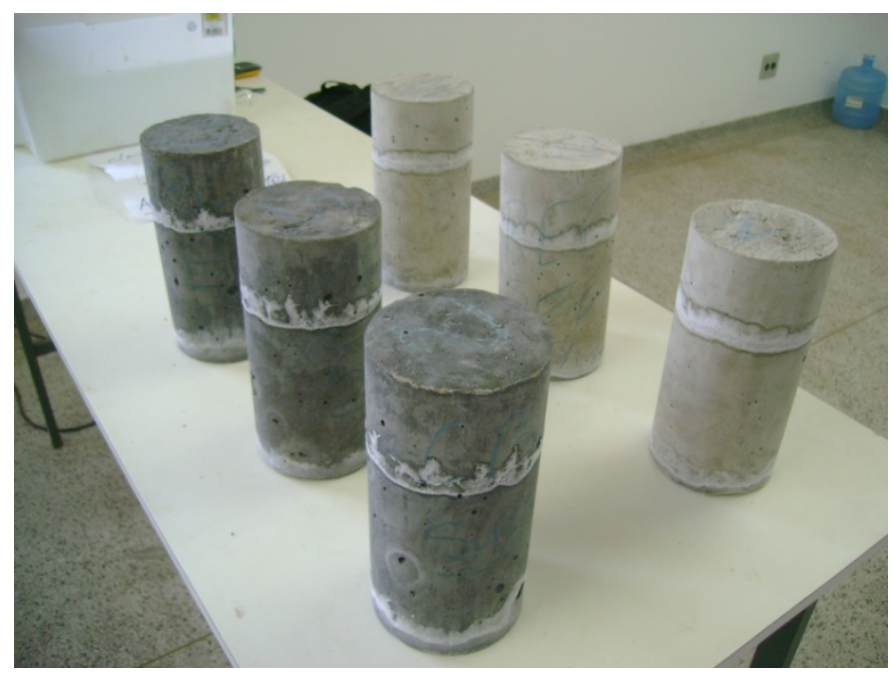

Figura 8: Em detalhe as faixas esbranquiçadas que identificam o local de reação entre o $\mathrm{AgNO}_{3}$ e o $\mathrm{NaCl}$ nos traços de concreto (corpos de prova escuros são os com incorporação de CBC).

ANJOS e MARTINELLI [34] concluíram na sua pesquisa que a CBC aperfeiçoou as propriedades do concreto estudado, assim como proporcionou redução na penetração de íons cloreto no concreto, até o valor avaliado de $20 \%$ de substituição de cimento.

GANESAN et al. [35] (2007) estudaram os efeitos da substituição parcial do cimento por CBC nas propriedades mecânicas e físicas do concreto endurecido. Os resultados mostraram que com uma adição de até $20 \%$ de CBC ao cimento ocorreu uma redução na difusão de cloreto, além de uma sensível resistência à penetração e um desenvolvimento de alta resistência inicial.

LIMA et al. [36] estudaram traços de concreto com CBC em substituição ao agregado miúdo e concluíram que com o teor de 30\% de CBC se obtém uma menor profundidade de carbonatação do concreto, comparando-se com seu respectivo traço de referência.

No caso dos ensaios de desgaste superficial por abrasão, o concreto com 20\% de CBC apresentou desempenho de 51,46\% superior ao concreto do traço referência. Notou-se que o desgaste superficial foi diferente nos corpos de prova utilizados, ou seja, a resistência ao desgaste aumentou com o incremento da resistência à compressão. Na Figura 9 pode ser observado o aspecto dos corpos de prova submetidos ao ensaio de abrasão, após 72 horas. 

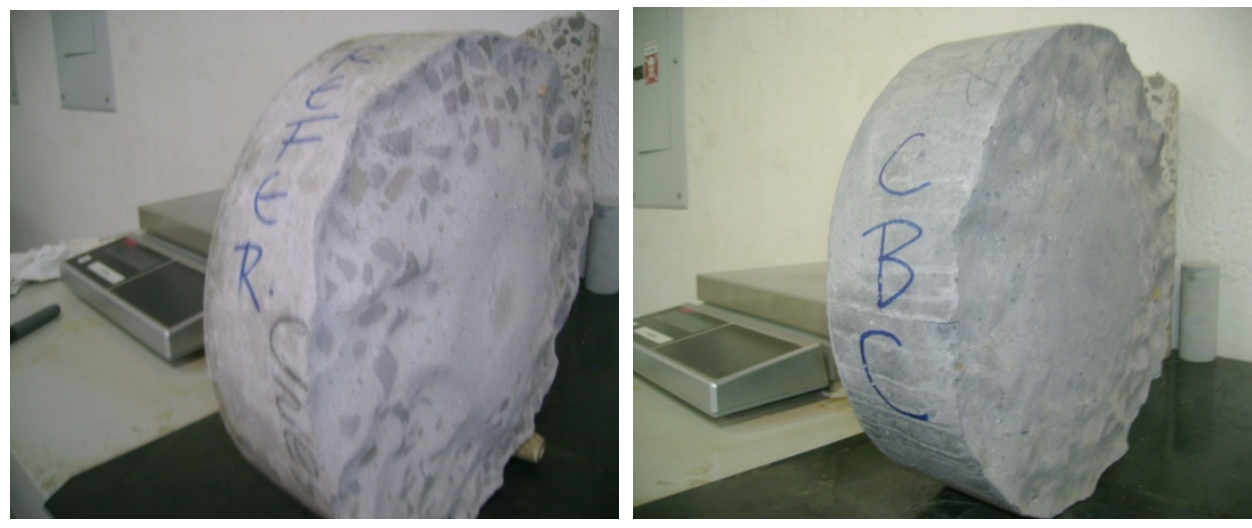

Figura 9: Aparência dos corpos de prova após desgaste de 72 horas: a) Corpo de prova referência; b) Corpo de prova com $20 \%$ CBC.

SIDDIQUE [37] estudou concretos confeccionados com cinza volante (classe F) em substituição ao agregado miúdo e atestou que a resistência ao desgaste aumenta com o aumento da resistência à compressão.

LIMA et al. [36] também realizaram ensaios de desgaste por abrasão e afirmaram que concreto produzido com 50\% de substituição de agregado miúdo por CBC obteve o melhor desempenho (menor desgaste superficial) entre os concretos que utilizaram o cimento do tipo CPII E 32.

\section{CONCLUSÕES}

Ao final das discussões realizadas observou-se melhor desempenho do traço com $20 \%$ de CBC em relação ao concreto de referência. $\mathrm{O}$ traço de referência apenas apresentou um melhor desempenho comparado ao traço com 20\% de CBC nos ensaios de absorção por capilaridade, diante disso, os valores obtidosforam considerados equivalentes entre si. Desse modo, pode-se concluir que:

(a) ocorre a redução do abatimento do concreto com a adição da CBC;

(b) o concreto confeccionado com o teor de $20 \%$ de CBC obteve valores de resistência à compressão e de resistência à tração por compressão diametral semelhantesao traço de referência;

(c) os valores de resistência ao ataque químico (ácido lático) entre o concreto com 20\% de CBC e o concreto de referência são de certa maneira similares;

(d) o traço com 20\% de CBC obteve a menor profundidade de penetração de cloretos, comparando-se com seu respectivo traço de referência; e

(e) o concreto produzido com 20\% de CBC obteve o melhor desempenho (menor desgaste superficial) quando comparado com o traço de referência.

Tendo em vista que o traço com CBC escolhido para os ensaios de durabilidade foi o de melhor desempenho na avaliação de propriedades mecânicas, neste caso o de $20 \%$ de substituição do agregado miúdo pela CBC, tem-se que a qualidade do concreto não foi comprometida com a adição deste material residual. Em relação ao tipo de aplicação para o concreto com $20 \%$ de CBC, levando em consideração todos os resultados obtidos, indicam-se aplicar este concreto na produção de artefatos para infraestrutura urbana (submetidos a ações abrasivas superficiais intensas), locais de maresias significativas (de contenção do ingresso de íons cloreto em sua superfície), além de estruturas aparentes de concreto armado.

\section{BIBLIOGRAFIA}

[1] CONAB, Acompanhamento da safra brasileira de cana-de-açúcar,v. 1, nº 3, Brasília: CONAB Companhia Nacional de Abastecimento, 2014.

[2] CORDEIRO, G. C., TOLEDO FILHO, R. D., TAVARES, L. M., FAIRBAIRN, E. R. M., "Pozzolanic activity and filler effect of sugar cane bagasse ash in Portland cement and lime mortars", Cement \& Concrete Composites, n. 30, pp. 410-418, 2008. 
[3] SALES, A., LIMA, S. A., "Use of brazilian sugarcane bagasse ash in concrete as sand replacement”. Waste Management, v. 30, n. 6, pp. 1114-1122, 2010.

[4] ROCHA, J. C., CHERIAF, M., Aproveitamento de resíduos na construção. Coleção Habitare: Utilização de Resíduos na Construção Habitacional, Porto Alegre, ANTAC, v. 4, 2003.

[5] GANESAN, K., RAJAGOPAL, K., THANGAVEL, K., "Evaluation of bagasse ash as a supplementary cementitious material”, Cement \& Concrete Composities, v. 29, n. 6, pp. 515-524, 2007.

[6] FRÍAS, M., VILLAR, E., SAVASTANO, H., "Brazilian sugar cane bagasse ashes from the cogeneration industry as active pozzolans for cement manufacture,Cement\& Concrete Composites, v. 33, n. 4, pp. 490-496, Apr. 2011.

[7] MACEDO, P. C. etal., "Revisãobibliográfica sobre o uso de cinza de bagaço de cana-de-açúcar na construção civil”, In: Congresso Brasileiro do Concreto - IBRACON, 51, Curitiba, 2009.

[8] ATIS, C. D., “Accelerated carbonation and testing of concrete made with fly ash”, Construction and Building Materials, v. 17, n. 3, pp. 147-152, 2003.

[9] SILVA, V. M.,Ação da carbonatação em vigas de concreto armado em serviço, construídas em escala natural e reduzida, Tese de D.Sc., EESC/USP, São Carlos, SP, Brasil, 2007.

[10] HELENE, P. R. L.,“Vidaútil das estruturas”,Téchne, n. 17, pp. 28-31, Jul./Aug. 1995.

[11] XUEQUAN, W., et al., "Study on steel slag and fly ash composite portland cement”, Cement and Concrete Research, v. 29, n. 7, pp. 1103-1106, 1999.

[12] ATIS, C. D., “Carbonation-porosity-strength model for fly ash concrete”, Journal of Materials in Civil Engineering, Technical Note, pp. 91-94, Jan./Feb. 2004.

[13] LIMA, S. A.,etal.““Análise de argamassas confeccionadas com a cinza do bagaço da cana-de-açúcar em substituição ao agregado miúdo”,Revista Tecnológica, v. 18, pp. 87-97, 2009.

[14] ASSOCIAÇÃO BRASILEIRA DE NORMAS TÉCNICAS - ABNT,NBR 11578: Cimento portland composto - especificação, Rio de Janeiro, 1997.

[15]ASSOCIAÇÃO BRASILEIRA DE NORMAS TÉCNICAS - ABNT,NBRNM 248: Agregados determinação da composição granulométrica, Rio de Janeiro, 2003.

[16]ASSOCIAÇÃO BRASILEIRA DE NORMAS TÉCNICAS - ABNT,NBR 12653: Materiais pozolânicos - requisitos, Rio de Janeiro, 2012.

[17] ASSOCIAÇÃO BRASILEIRA DE NORMAS TÉCNICAS - ABNT,NBRNM 67: Concreto determinação da consistência pelo abatimento do troco de cone, Rio de Janeiro, 1998.

[18] ASSOCIAÇÃO BRASILEIRA DE NORMAS TÉCNICAS - ABNT, NBR 5738: Moldagem e cura de corpos-de-prova cilíndricos ou prismáticos de concreto, Rio de Janeiro, 2003.

[19] ASSOCIAÇÃO BRASILEIRA DE NORMAS TÉCNICAS - ABNT, NBR 5739: Concreto - Ensaios de compressão de corpos-de-prova cilíndricos, Rio de Janeiro, 2007.

[20] ASSOCIAÇÃO BRASILEIRA DE NORMAS TÉCNICAS - ABNT, NBR 7222: Concreto e argamassa - determinação da resistência à tração por compressão diametral de corpos de prova cilíndricos, Rio de Janeiro, 2011.

[21] ANDRADE, J. J. O., TISBIEREK, F. T., RATHER, L. P. R.,et al.,“Avaliação das características do concreto quando submetido à degradação de origem química”. In: Congresso Brasileiro do Concreto IBRACON, 45, pp. 1-12, Vitória, 2003.

[22] DAL MOLIN, D.,etal.,"Estudo de concretos com adição de sílica ativa (microssílica) frente ao ataque de agentes agressivos para emprego em pisos especiais”,In: InternationalCongresson High-Performance Concrete and Performance andQualityof Concrete Structures, 1, pp. 590-598, Florianópolis, 1996.

[23] ASSOCIAÇÃO BRASILEIRA DE NORMAS TÉCNICAS -ABNT,.NBR 9779: Argamassa e concreto endurecidos - determinação da absorção de água por capilaridade, Rio de Janeiro, 1995.

[24] SILVA, F. G.,Estudos de concretos de alto desempenho frente à ação de cloretos, Tese de D.Sc., EESC/USP, São Carlos, SP, Brasil, 2006.

[25] AMERICAN SOCIETY OF TESTING MATERIALS - ASTM, C 1138: Standard test method for abrasion resistence of concrete - underwater method, West Conshohocken, Pennsylvania, USA, 2005.

[26] MODANIA, P. O., VYAWAHAREB, M. R., "Utilization of bagasse ash as a partial replacement of fine aggregate in concrete”, Procedia Engineering, n. 51, pp.25-29, 2013. 
[27] MOLIN FILHO, R G. D., Concreto autoadensável com a utilização da cinza do bagaço de cana, Dissertação de Ms.C., UEM, Maringá, PR, Brasil, 2012.

[28] CORDEIRO, G. C., Utilização de cinzas ultrafinas do bagaço de cana-de-açúcar e da casca de arroz como aditivos minerais em concreto, Tese de D.Sc., UFRJ, Rio de Janeiro, RJ, Brasil, 2006.

[29] GIAMMUSSO, S. E.,Manual do concreto, São Paulo,Pini, 1992.

[30] SOUTO, J. M. F., Avaliação do desempenho da cinza do bagaço de cana-de-açúcar na produção de concretos, Dissertação de M.Sc., UEM, Maringá, PR, Brasil, 2010.

[31] SINGH, N. B., SINGH, V. D., RAI, S., "Hydration of bagasse ash-blended Portland cement”, Cement and Concrete Research, v. 30, n. 9, pp. 1485-1488, 2000.

[32] BAGUANT, K., "Properties of concrete with bagasse ash as fine aggregate", In: International Conference on Fly Ash, Silica Fume, Slag and Natural Pozzolans in Concrete - CANMET/ACI, 5, pp. 315337, Milwaukee, USA, 1995.

[33] MACEDO, P. C., Avaliação de argamassas com adição da cinza do bagaço de cana-de-açúcar, Dissertação de Ms.C., FEIS/UNESP, Ilha Solteira, SP, Brasil, 2009.

[34] ANJOS, M. A. S., MARTINELLI, A. E., (2008) "Caracterização do resíduo da biomassa da cana-deaçúcar para aplicação em pastas cimentícias", In: Congresso Brasileiro de Engenharia e Ciência dos Materiais - CBECiMat., 18, Porto de Galinhas, 2008.

[35] GANESAN, K., RAJAGOPAL, K., THANGAVEL, K., "Evaluation of bagasse ash as supplementary cementitiousmatérial”, Cement \& Concrete Composites, v.29, pp. 515-524, 2007.

[36] LIMA, S. A. etal.“"Análise de argamassas confeccionadas com a cinza do bagaço da cana-de-açúcar em substituição ao agregado miúdo”,Revista Tecnológica, v. 18, pp. 87-97, 2009.

[37] SIDDIQUE, R., "Effect of fine aggregate replacement with class fly ash on the abrasion resistance of concrete", Cement and Concrete Research, v.33, n.11, pp. 1877-1881, 2003. 